\title{
Using Ecological Asset Mapping to Investigate Pre-Service Teachers' Cultural Assets
}

\author{
Noah Borrero \\ University of San Francisco \\ U. S. A. \\ Christine Yeh \\ University of San Francisco \\ U. S. A.
}

ABSTRACT: We examined the impact of a pedagogical strategy, ecological asset mapping, on 19 pre-service teachers' self-exploration, development of respect for others, and critical examination of social injustice. Data were analyzed from participants' ecological asset maps and essays describing the experience of completing and sharing the maps. The analysis of the maps generated two themes, transitions over time and multiple identities; four themes emerged from the essays such as navigating support systems, self consciousness, process as pedagogy, and consciousness raising. Findings suggest ecological asset mapping can be a powerful pedagogical tool in supporting pre-service teachers' self-awareness, respect for others, exploration of cultural assets, and development of critical consciousness.

KEYWORDS: asset mapping, pre-service teachers, social justice

\author{
Theoretical Framework \\ Method \\ Findings \\ Reflections on Ecological Asset Mapping \\ Discussion and Implications \\ References \\ Author Contact
}

During a recent classroom visit, a first-year teacher was walking through the room with a clipboard listing the names of "target students." These were the students her administration was requesting that she pay specific attention to, as they had been identified as "below basic" or "basic" on the most recent benchmark assessments that the school had given. These were students believed to hold the most potential to become "proficient" in time for the upcoming statewide tests. While it was not clear if the teacher had completely bought into this strategy, it was clear that this was yet another form of reductionist categorization of students. In addition to these existing labels, students are also defined by what they supposedly cannot do: "English Language Learner," "At Risk," "Emotionally Disturbed," "Speech Impaired," to name a few. 
We now have even broader categories determined by the bubbles that students fill in on benchmark tests designed to prepare them for the "real" test.

In this particular school, these labels reflected the larger racial chasm between students of color and White students and had many of the former placed in remediation for the majority of their school day. Yosso (2005) states that "one of the most prevalent forms of contemporary racism in US schools is deficit thinking" (p. 76) and our educational system continues to manufacture labels that lead to this way of thinking. Contrarily, Yosso's (2005) work also speaks to growing scholars who voice that we must combat this deficit narrative of students of color by developing theoretical approaches, empirical inquiry, and pedagogical strategies that foster communities' strengths and cultural wealth.

\section{Theoretical Framework}

In the current study, we seek to build upon foundational work in the study of cultural and community strengths (e.g., Camangian, 2010; Martínez, 2010; Moll, Amanti, Neff, \& Gonzalez, 1992; Paris, 2010; Yosso, 2005) to support this counternarrative. Specifically, using Picower's (2012) social justice curriculum as a guide for moving students towards social action, we developed, implemented, and explored the use of Ecological Asset Mapping (EAM) on pre-service teachers' examination of their own cultural assets. We believe this approach has the potential to counteract deficit assumptions about students in two meaningful ways. First, EAM may facilitate teachers' self-awareness, relationship building, sense of community, and critical consciousness. Second, as a pedagogical strategy embedded in a larger social justice curriculum, this approach encourages teachers to explore and see their own students far beyond narrow test scores and, instead, from the framework of community and cultural wealth (e.g., Duncan-Andrade, 2007; Ladson-Billings, 1994; Villegas \& Lucas, 2002; Villegas, Strom, \& Lucas, 2012).

\section{Teaching for Social Justice}

We seek to address the lack of research that exists between theoretical understandings and pedagogical practice as it pertains to the larger notion of cultural assets. While much of this literature presents compelling conceptualizations of students' cultural worth, there is opportunity to more specifically connect these ideas to pedagogical strategies for classroom teachers (e.g., Gunn, Bennett, Evans, Peterson, \& Welsh, 2013). To make such a collective impact as educators, we must infiltrate the structures enforcing deficit labels on multiple levels (Akom, 2009; Ladson-Billings, 2016; Valenzuela, 1999), and we see the current project as both a theoretical and pedagogical tool for doing so. 
EAM is a pedagogical strategy embedded in a larger theoretical framework for social justice. Picower (2012) delineates six elements of social justice curriculum design focusing on (a) knowledge and self-love, (b) respect for others, (c) issues of social injustice, (d) social movements and social change, (e) awareness-raising, and (f) social action. Although these elements were initially intended for the elementary school curriculum, they also provide an important conceptual framework for pre-service teacher education. Our approach to EAM is embedded in the first three elements that focus on self-exploration, respect for others, and issues of social injustice.

The purpose of the EAM activity was also to promote self-exploration and critical consciousness among pre-service teachers. Self-exploration cannot be viewed simply as an act of introspection and self-awareness that ends with the individual (Kohli, 2009). Rather, we contend that self-awareness and one's positionality must be considered across intersecting and dynamic settings that shape and influence one's worldview and cultural identities (Freire, 1970; Villegas et al., 2012). Theoretically, EAM intentionally allows pre-service teachers to explore their positionality across meaningful ecologies through active selfreflection of the spaces and interactions that promote and deter the emergence of cultural assets. Specifically, exploring assets in different and overlapping ecological contexts uncovers opportunities for interrogating oppressive forces. In this way, EAM is both a pedagogical strategy and a theoretical framework that seeks to promote self-love and knowledge, respect for others, and the critical examination of social and educational inequities. These foundations of EAM help to foster praxis for teachers and scholars focused on the issues of equity and access that are central to multicultural education (e.g., Convertino, 2016).

\section{Ecological Systems Theory}

Schools are cultural communities that must be understood and conceptualized as dynamic and intersecting ecological contexts (Bronfenbrenner, 1989; Lee, 2008). Our focus on EAM as a pedagogical strategy reflects our focus on recognizing and harnessing teachers' cultural assets as well as the perspective that cultural and socioeconomic diversity are critical assets in school settings (Borrero \& Yeh, 2013; Nieto, 2002). As such, an ecological, asset-based approach benefits students from different backgrounds and allows for a conceptualization of schools as part of the larger neighborhood and community (e.g., Moll et al., 1992). This perspective of teachers and students as embedded in a larger community increases the opportunities for teachers and students alike to build connections between theory and practice and the learning that they are doing outside of school (e.g., with family, peers, and other community members) with their classroom learning. Viewing cultural assets as ecological also strengthens our sociocultural approach (Nieto, 2002; Vygotsky, 1978) to the development of critical consciousness and our priority on community building. 
Specifically, EAM stems from a belief that cultural assets overlap, intersect, and develop across multiple contexts. Bronfenbrenner (1994) has proposed a development-in-context theory that supports the notion that teachers' assets are inextricably linked to their interactions and relationships across students, peers, families, neighborhoods, and cultural settings. According to ecological systems theory, human development is nested within five environmental systems that exert bi-directional influences within and between the systems. The microsystem consists of an individual's biology and immediate settings (e.g., family, neighborhood, school, and peers). The mesosystem comprises links and connections between multiple immediate environments (e.g., students, teachers, family, and neighborhood). The exosystem involves developmental influence from a setting in which the individual does not have an active role (e.g., resources teachers have access to). The macrosystem encompasses the cultural context (e.g., political system, racial/racist school climate), including the values and customs of society. The chronosystem refers to the socio-historical circumstances and conditions that accompany or transition throughout the individual's course of life (i.e., zeitgeist such as liberation from slavery, marriage equity legislation).

Given these foundations of ecological theory, teachers' cultural strengths cannot be separated from the social contexts in which they occur. These assets are realized through social interactions in the multiple contexts teachers navigate daily (Gutierrez \& Rogoff, 2003; Ladson-Billings, 1994; Lee, Spencer, \& Harpalani, 2004; Lee, 2008), and teachers learn to adapt and build their strengths according to the environment, situation, and interpersonal dynamics (Hawkins, 2004; Orellana \& Bowman, 2003).

EAM also serves as a pedagogical model for teachers. It is intended to offer reflection, awareness, and interrogation of self (Borrero, Flores, \& de la Cruz, 2016) and community building for teachers and students. In this waywhen connected with our sociocultural approach to learning-it is designed to contribute to how we understand the experiences of K-12 students through their connections with significant others. Students' ecological assets are cultural activities that shape identities, relationships, and sense of belonging in school spaces (Gutierrez \& Rogoff, 2003; Nieto, 2002). For example, research on ecological language learning found that bilingual students navigated multiple relational contexts when learning English in and outside of school (Borrero \& Yeh, 2010). This extends traditional notions of cultural assets as contained or owned by a particular individual and connects with research that showcases the intersections of race and language with students learning English in urban communities (e.g., Olsen, 1997; Paris, 2010).

\section{Cultural Assets}

We conceptualize cultural assets as learned, intergenerational, fluid ways of being that reveal meaningful relationships, historical legacies, and filial 
traditions. These assets are represented in communal and cultural qualities that we possess and collective actions we take. For example, previous research highlights the bilingualism of middle school Latino/as as an asset that not only provides them access to multiple social and academic contexts, but also creates opportunities for self-reflection and cultural pride that their classmates do not have (Borrero, 2011; Martinez, 2010). Further, research with Samoan high school students and community workers showcases generosity as a cultural asset across generations and contexts in a way that prepares youth to give back to future generations in spite of institutional barriers (Yeh, Borrero, Tito, \& Petaia, 2014). In these ways, we envision cultural assets as collective resources that are harnessed by a group. In relation to ecological theory (Bronfenbrenner, 1989), and particularly for youth, it is often the navigation of multiple cultural contexts (e.g., home, school, peer, and neighborhood) that display these resources.

Our vision of cultural assets is built upon foundational work in the social sciences. Developmental assets (Benson, Lefferts, Scales, \& Blythe, 1998) and funds of knowledge (Moll et al., 1992) are key frameworks from which we draw both theoretically and empirically. This research teaches us to pursue new modes of inquiry and variables for investigation. Further, Yosso's (2005) model for community cultural wealth positions linguistic, resistant, familial, aspirational, social, and navigational capital as fundamental forms of wealth that we must not only recognize, but we must empirically investigate to begin to tell the stories of youth and communities of color. We are particularly drawn to these conceptualizations of capacity as they reveal a part of cultural assets that is as much about process as it is about product. We are also eager to work towards conceptualizations of youths' strengths that reach beyond monetary and capitalistic categorizations of worth.

Teacher educators and researchers have emphasized the critical role of cultural assets as a guiding frame for working with marginalized communities in public schools (Yeh et al., 2014; Camangian, 2013). Yet specific pedagogical strategies directly linked to enacting a cultural asset-based teaching model are not fully realized, and research in this area is just beginning. For example, Martínez (2010) explores the multiple, cross-disciplinary literacy strengths of a group of supposed "English language learners" in a middle school context. Yet, the connections between these students' linguistic assets and the pedagogy of the classroom are unexplored. Similarly, while our previous research (e.g., Borrero, 2011; Borrero, Yeh, Cruz, \& Suda, 2012) has investigated students' navigational acumen across classroom and cultural contexts, we have yet to examine pedagogical practices that support such learning. Camangian (2010) explored the pedagogical implications of teaching "autoethnography" in a high school classroom and its impact on youths' perceptions of self and its place in classroom curriculum. We seek to enhance this research by implementing a theoretically-based classroom practice for a group of pre-service teachers that they can participate in and then (ideally) envision as a part of their classroom practice. 
Hence, we implemented the use of EAM as a pedagogical strategy in a pre-service teacher graduate course and analyzed maps created by these teachers to see what themes emerged from this exploration. In addition, we asked the same pre-service teachers to reflect on their experience creating and sharing their EAM in an essay and analyzed those narratives.

\section{Description of Ecological Asset Mapping}

EAM was developed to help teachers examine and recognize the depth and complexity of cultural assets from a relational and contextual perspective. EAM also serves to develop teachers' self-awareness by helping them explore their own interactions in levels and systems of oppression. In total, the EAM activity could be described as five interrelated projects:

1. the development of an Ecological Asset Map;

2. a gallery walk where teachers view each other's maps and receive a feedback sheet from their peers;

3. a reflection paper on the process of making the EAM and participating in the gallery walk;

4. group asset mapping and analysis of school and/or community contexts; and

5. research presentation on (in)effective teaching that acknowledges and utilizes cultural assets in educational spaces.

For the purposes of this study, we focused on the project \#1 and \#3 above. (See Table 1 for the EAM prompts that students received.)

\section{Method}

This study was conducted with undergraduate and graduate students in a course. In this section, details about the participants, research procedure, and data analysis are provided.

\section{Participants}

Participants included 19 pre-service teachers in a course focused on diversity and social justice in teaching. Among the participants, nine were undergraduate and ten were graduate students. Among the undergraduates, eight were female and one was male; one was identified as biracial, two as Latino/a, three as Asian American, and three as White. Among the graduate students, seven were female and three were male; one was identified as African American, one as Latino, and eight as White. In terms of teaching background, 
students came with a range of experiences. The nine undergraduate students were all dual degree majors in education with a stated interest in pursuing their teaching credential. All of these students were beginning to observe master teachers and spend time in local schools as part of their coursework. All of the ten graduate students were in the process of completing teaching fieldwork that placed them in public schools in the San Francisco Bay Area in California.

Table 1

Ecological Asset Map and Reflection Prompts for Students

MAP: Using the theoretical foundations we have studied thus far (e.g. ecological and sociocultural theory) and your own perspectives of the multiple contexts you navigate, portray your greatest strengths. This can be in the form of a map, but does not have to be. It must be some type of display that your classmates can view and interpret without your explanation (we will do a gallery walk in class). Some questions that you might consider: What are your cultural assets? What/Who/Where has most helped you achieve your successes? Where do you go for support? What has lead you to become a teacher? What/Who/Where helps you grow and learn?

REFLECTION: Write a 2-page (maximum) paper in which you dig deeply into 1-2 key reflections from the process of making your ecological asset map and participating in the gallery walk (and debrief). The goal is to push your thinking about theory and your ideas about cultural assets. Do not explain your map, but rather, express your ideas and feelings about exploring positionality in the context of this course. Cite at least 2 readings from the course in your paper.

\section{Procedure}

IRB approval was granted by the host institution for EAM as a quality improvement project. Students were given the instructions for the five assignments/activities during a class session, and time was provided to answer questions and concerns. The assignments were embedded within an ecological and a sociocultural framework, and students were given key readings in advance and then discussed these theories in class prior to completing the work (e.g., Bronfenbrenner, 1994; Nieto, 2002). Further, Yosso's (2005) model of community cultural wealth was read and discussed as a part of the preparation for the EAM project.

We used grounded theory as our investigative and conceptual methodology because it focuses on the development of theory through the systematic gathering and analysis of data (Taylor \& Bogdan, 1998). Since we were developing and evaluating a new pedagogical strategy, grounded theory was a relevant methodology for the purpose of generating theory in our 
exploratory research study. In this study, we triangulated the data by including analysis of the actual maps, as well as the students' reflections on creating the map and participating in a gallery walk. Hence, we were interested in comparing the content of the maps and the experience of creating the maps as part of our larger understanding of the impact of our pedagogical approach.

\section{Data Analysis}

Although the five assignments generated multiple potential sources of data, we focused on assignments one and three only for the purposes of understanding the impact and use of EAM. This resulted in 19 student ecological asset maps and 19 student reflection papers about creating the maps and their experiences with the gallery walk of the maps during class time. Using grounded theory (Glaser \& Strauss, 1967), these data were coded to identify patterns and themes and missing items (i.e., pre-service teachers not identifying assets in certain contexts).

We used "open coding," which entailed multiple readings of the data for any images, figures, words, or sentences that had potential meaning for our project. We then organized similar themes and concepts into groups and used "axial coding" to gain a deeper understanding of the context, circumstances, and outcomes of these categories (Strauss \& Corbin, 1990). An example of axial coding involved concepts such as sharing, validation, connection. These concepts were grouped into one category, which we termed "community building," and possible relationships between the subcategories were analyzed. We next performed "selective coding," which involved coding in terms of one core variable (Glaser \& Strauss, 1967; Strauss, 1987) and connecting it to other categories (Strauss \& Corbin, 1990). This process encouraged us not only to think carefully about each category, but also continually compelled us to improve and reexamine our core categories.

During the open coding process we noticed strong differences between codes and themes emerging from the maps in comparison to the reflection papers. The maps appeared to focus specifically on the participants' visual representations of their assets across meaningful ecologies in their lives, whereas the reflection papers were written after the map gallery walk and included student narratives about the meaning of this assignment and the process of sharing. We consciously decided to divide the analysis into two stages to allow deeper and specific understandings to emerge in each of the assignments. As described by Futch and Fine (2014), maps allow us to "consider the increasing importance of methods that are able to resist the hegemony of the written word and draw on the complexities of our interconnected life spaces" ( $p$. 42). These authors also speak to the use of mapping as part of a multi-method research approach to access multiple, layered dimensions of selves. When possible, we compared the maps and the reflections for each participant to explore process as well as content in ecological asset mapping. In further 
support of this approach, Marshall and Toohey (2010) discuss the importance of using multi-modal texts and analyses to explore the dynamic and inter-related representations of self. We feel that our analyses of the maps and written reflections provided this type of exploration.

\section{Findings about Ecological Asset Maps}

We separately analyzed the Ecological Asset Maps to best understand and explore participants' visual representations of their assets as ecologically framed and presented. This produced a range of maps and artistic styles, as participants used multiple media to create their personal map. Materials and content included photos, drawings, collage, words, charts and a number of other display techniques. The analysis resulted in two main themes, Transitions and Multiple Identities, which we later connect with themes that emerged from the reflection papers.

\section{Transitions over Time}

The maps revealed changes over time that represented core events, critical incidents, and important locations, places, and life periods. These transitions seemed to capture the situation specificity and flexible nature of assets by showing assets as embedded and in movement in time and space. Within this theme, maps revealed the subthemes of geographic transitions, time periods, and navigating relational contexts.

Participants frequently created maps of the different geographic transitions and locations they have made. This includes living in and visiting different countries and cultures and moves to different cities for school or work. Cara (pseudonyms are used throughout to protect participants' identities) painted and cut out a map of the world with 10 different places marked with an $X$, and identified $X$ as "where my heart is." Nicole also included a map of the world with color-coded dots scattered to places she had visited and lived. Linda cut out magazine photos to represent different states that she has lived in and placed these in bold circles across her map with the Douglass Adams' quote, "I may not have gone where I intended to go, but I ended up where I needed to be." Alma included pictures of flags from different countries she feels connected to including India, Nicaragua, Italy, and Guatemala. These examples allow the viewer to see the author in movement and see how location fostered unique assets. The maps with transition themes also provide spatial temporal information (Futch \& Fine, 2014) that highlight self-in-relation information, as self is inevitably interconnected with location and movement.

In addition to displaying geographic locations, participants created maps that represented specific time periods. Lana created a timeline with specific dates 
lined up on the bottom of her large map and key life periods documented by year. These included childhood, parents' divorce, the birth of her brother, high school graduation, a severe medical illness, and the beginning of graduate school. For Lana, this included a timeline of the past eight years of her life and a specific narrative description of each of these years as it related to her schooling: "2/24/15 Senior, dual degree (teaching program), excited for my future career, wouldn't be here today without the choices I've made in the past good or bad!" Lara sees each time period as a necessary transition with a cumulative impact over time. The maps not only represented relevant transitions over time that were experienced by the participants, but also specific navigations across relational contexts.

Participants visually and verbally described how they navigated different relational contexts. Alexandra portrayed assets via her "Road to Success." This pictorial journey included photos of key people in her life from her family, high school, co-workers at camp, teachers, and her current friends. She described these "significant people" as folks who have contributed to her success. Her transitions revealed layered stories of significant relationships and influences that supported her growth over time. Manuel created a tri-fold map comprised almost entirely of photos of people in his life. These included close friends, family members, romantic relationships, teachers, and teammates in sports. Each photo included a brief description of the value or asset associated with the relationship: "FAITH", "FORGIVE", "circle of success", "mentorship", "brotherhood, friendship, family," etc. From Manuel's map, you could sense the multiple interpersonal settings and connections fostered his own shifting beliefs, values and assets. Each relationship allowed him to develop a particular strength in a reciprocal and meaningful dynamic.

\section{Multiple Identities}

The multidimensional and relational dynamics described in participants' transitions underscore how participants also created maps displaying and revealing multiple identities. According to Futch and Fine (2014), "Maps answered the critical historical call of early social psychology to consider the typology of life spaces, the subjectivity of individual, social representations and de-center the more traditional and hierarchical aspects of research participation endemic to our field (p. 21)." This included making sense of their experiences of holding multiple complex and often contradicting identities simultaneously. These identities represent ethnic and racial spaces, alliances to different cultural organizations, groups, and communities, and differing and changing descriptions of self. Sub-themes that emerged were cultural identities, group identities, and possible identities, and these subthemes intersected and interrelated in meaningful and complicated ways.

Through words, photos, narratives, quotes, and collage, participants portrayed the complexity and relevance of holding multiple cultural identities. Mila 
and Alex discussed being of "mixed" racial heritage. Alex, who holds both a Filipino and Chinese identity, shares, "My ethnicity defines my racial identity and has informed how I act upon it." Lana has her cultural identities grouped inside one of many nesting dolls and has cut out words pasted inside, American, American, English, Swedish, Lutheran, Scots-Irish, moderate democrat, lower middle class, and public school educated. Their layered visual representations with photos interacting and dialoging with words and images allow the student to portray multiple selves beyond the strict and reductionist categories of race and ethnicity. All too often individuals of multiracial and multiethnic heritage are "othered" into spaces of not belonging or fitting in (Borrero et al., 2012). The ecological asset map prompted and, in a sense, promoted spaces that allow for multiple identities to co-exist.

Group identities included involvement that the participants had in various clubs, organizations, sports teams, etc. that helped them to define their identities and their assets. For example, Diana's map was a display of more than a hundred words with prominent features of her identities in large, colorful print. Samples of some of her group identities included her involvement in sports such as "lacrosse" and "cross country." These labels represent important connections to such groups as a way of belonging and seeing aspects of the self as engaged in and in relation to a larger group experience.

Identities were comprised not only of existing, multilayered identities but of aspirational and possible selves. Lisa's primary display on her map was the statement, "I want to become a teacher because..." revealing her desire and hope to be a teacher one day. This included an inspirational note from a former teacher that has inspired her and her possible self as a teacher. John's map had a collage of magazine photos including his many possible selves as one day striving to be a dad, musician, and crane operator which allowed for considering multidimensional gendered and occupational identities which could be seen as in contradiction in more traditional and limited spaces. Irene's three-dimensional sculptural map included Lego blocks increasing in height and numbered in a circle. The highest number symbolically represented her ultimate goal and was displayed by a basketball hoop and NCAA basketball sign. Michelle created a powerful visual display of possible identities that were aligned with critical consciousness and an awareness of her own power and privilege. This was the only map that clearly identified with ideas about raising consciousness, so a separate category was not created.

\section{Reflections on Ecological Asset Mapping}

We separately analyzed the EAM reflection papers to explore the ways that students thought and felt about the process of making their maps and participating in the gallery walk with their colleagues. These papers were written a week after the initial maps were shared and were intended to prompt deeper thinking about their own as well as their colleagues' maps and reactions. The 
analysis of the reflections resulted in four main themes: navigating support systems, self-consciousness, process as pedagogy, and consciousness-raising.

\section{Navigating Support Systems}

As with the ecological asset maps, nearly all of the reflection papers addressed personal supports as a foundation for their cultural assets. These personal supports were largely relational, but students also wrote about different contexts in which their assets emerged and the navigation of these different relationships and spaces. The sub-themes that make up this larger theme are connections between and among important people, places and spaces of value, and navigating multiple contexts.

In reflecting on the process of making their maps, students discussed the role of key people in their lives as major assets. Many students wrote about portraying family members as a starting point for the assignment and for their thinking about their own development and growth. For example, John shared:

...to begin the process of making sense of my own life, I had to think first about the major people and events that have factored into it, and to then decide if they had an effect on whom I see myself as being. In the beginning, there were the obvious decisions: my wife, my parents, and sister...But once I began digging in, I began to see other connections as assets I hadn't given much thought to.

John goes on to talk about a key moment of support by his father that led to him re-focusing on a college education. The process of reflection allowed John to think through the different aspects of his map and how his life was interrelated with multiple ecologies. This process of reflection also allowed John to consider the specific impact or weight of the relationships in his life, his life experiences and how some were more powerful than others.

In addition to the idea of starting the project with a focus on key relational assets, students also focused on the ways that their relationships shaped their aspirations and career trajectories at very early ages. Not all of these examples were positive points of reflection for students, and some participants grappled with more challenging experiences as influencing their journey. For example, Michelle started her paper stating,

Peripherally political, I possessed a requisite compassion for racial, class and gender struggle, but with an abstract understanding of what those struggles comprised. As an African-American woman, this may seem unexpected, but my upbringing was comfortably upper-middle class and my parents eager to assimilate.

She then goes on to talk about her consciousness and understanding of power and inequity not really beginning until her graduate studies. She shares this part of her journey as an asset that largely came out of her own frustrations. 
Relatedly, she then she goes on to say that teaching is her chosen path to make sure this does not happen to students like her in future generations.

As with the naming of important people in their lives, students reflected on the different contexts in which their assets emerged, how they portrayed this on their maps, and what they noticed in seeing their classmates' maps. School was a salient context and most students identified their academic successes as playing a key role in their conceptualization of cultural assets. There was, however, variability as a number of students discussed school as a place that did not acknowledge their strengths. Alma wrote:

Personally, I thought of both negative and positive macro-sociological impacts when completing the ecological asset map for myself because adversity and opportunity have both played key roles in shaping my own success. When viewing my own cultural capital, I have learned to recognize what isn't usually valued in schools, and in the educational institution overall. My unique cultural capital has contributed to my success, even if it wasn't part of the dominant form of culture.

Reflections like this reveal that students were thinking about cultural assets as being embedded in and impacted by multiple systems and being fostered through challenges as well as through the privileges in their lives. The reflections papers allowed students to consider the interaction of support systems as intertwined within ecologies.

Building on the reflections about their important support networks, students wrote about their own abilities to thrive in different contexts with the help of different people. They wrote about the different roles they saw themselves fulfilling (e.g., daughter, uncle, friend, teacher, mentor, student) and how these different roles simultaneously make them who they are. Recognizing the ability to take on these different roles in different contexts (e.g., home, school, neighborhood, online) was a part of how students reflected on their own assets. There was also the acknowledgment of certain labels or expectations that students felt they had to live up to as a part of fulfilling certain roles. Not only did they write about being a daughter or an uncle for example, but they reflected on cultural labels and assumptions about race, gender, and class. Again, the navigation of these labels across different contexts was recognized as an asset. For example, Cara wrote:

In all cases, I have learned to navigate. I have learned the stereotypes, the assumptions, the expectations, the access, the denial, and the reality of these labels. And it is a privilege that I am able to live both inside and outside of those spaces in a dialogical, transformative way, because I was given the knowledge and tools to do so.

This quote portrays the interconnectedness of different support networks and how this student sees her ability to move across and between different cultural contexts as an asset. The students' navigational capital (Yosso, 2005) emerged from having to contest, interrogate, and confront various challenges and privileges. In this regard, these navigational skills and assets developed over 
time and in contexts. Having students reflect upon the different support networks in their lives deepened their understanding and appreciation of how navigational capital allowed them to receive as well as provide support across meaningful networks in reciprocal ways.

\section{Self-Consciousness}

In addition to naming their support networks, students discussed their personal journeys and the introspection involved in making the map and sharing it with others in the class. Within this theme, sharing successes and failures and vulnerability arose as salient factors in students' written reflections. This vulnerability is important to note and acknowledge since the ecological asset mapping technique intentionally brings the person into the educational space-a pedagogical approach that builds solidarity and awareness.

Students expressed the fact that making their maps was difficult. It was a challenging process to think about their own assets, and perhaps even more challenging was determining what to portray for their colleagues to see. As is mentioned in the theme above, many students did focus on key academic achievements - for example, higher education emerged as a salient academic asset-and they reflected on the journey towards reaching certain milestones. As a part of this reflection, students also shared about how they were drawn to remember the challenging times, the failures, and the ability to overcome adversity. For example, Manuel wrote:

In my effort to fully capture a multi-faceted journey, that is life, I could not help but gravitate to the roadblocks, pitfalls, and adverse conditions that I encountered along my path. Most people would deem this type of thinking as negative or view it as a deficit perspective, yet the results for me created a dichotomous effect when conjuring up such memories. Without these trying times, the fabric of my core would never have been fully cultivated. From my vantage point, adversity was the seed to grow my success and fortify the root that would sustain my growth.

This sense of identifying and reflecting on cultural assets as a process and a growing experience was important for students as they created their maps and viewed the maps of their classmates.

In thinking about the assets they wanted to portray, how to present them, and what their classmates might think of the finished map, students reflected on feeling uneasy and even anxious about the gallery walk. Students expressed wondering "how deep do I go" immediately when they started making their maps, and this question loomed throughout the process. Lara shared:

Looking back on my thought process for putting together my map I have more criticisms than I do personal compliments. When I walked into the classroom that day I felt confident with my map but was immediately 
overwhelmed with a feeling of insecurity, as I looked around the room sheepishly at the work everyone else was presenting. Disheartened and self-conscious I walked around and judged myself against my classmates. My map was bland, I thought, as I looked around longingly at other peoples work.

Lara went on to write about ultimately feeling appreciative for this level of questioning, and it was this type of self-deprecation by those who felt they censored too much and their sense of appreciation for others who "went deep" on their maps that was clear in students' reflection papers.

Students shared feelings like "righteousness" and "guilt" in thinking about their own maps, and "honor" and "inspiration" in witnessing others'. This emotional aspect of reflecting upon cultural assets became something that students reflected on as an important part of the process. Diana wrote, "The selfeffacing nature of this project required a level of openness and willingness towards vulnerability that I greatly appreciated." In thinking about the personal and communal aspects of this assignment, students' self-reflection was impacted.

\section{Process as Pedagogy}

As pre-service teachers, students certainly revealed a level of analysis in their reflections that focused on their growth as teachers and their desires to build meaningful relationships with their K-12 students. The emergent subthemes in this area were community building, connecting with youth, and building on youths' literacies.

Many students wrote about the payoffs of the vulnerability they felt in making their own maps. They wrote about the value of seeing the journey of others, the diversity of experiences represented by the maps, and the idea of "better-understanding self to better-understand others." In this way, there was a sense of universality revealed. For example, Nicole wrote, "I felt as though people were willing to take a risk and disclose information that revealed a lot of their life and characters. Similarly, when others affirmed assets I had claimed for myself via the comment sheet by my map, I felt strongly validated and understood." And it was in this sense of community building that students made the connection to their own teaching and desires to build community in their own classrooms, or as Lana wrote, "This layered activity that allowed for a lot of personal feelings and solidarity was an interesting warm up to how I think putting my pedagogical theories into practice."

Other students reflected on this very idea of connecting theory with practice by writing about the ways that the making and viewing of asset maps encouraged them to think about activities to share stories in their own classrooms. They wrote about wanting to find space to share about themselves with youth and for youth to hear each other's stories as a part of classroom 
learning. The diversity of stories was again important here, as students reflected on the need for youth to understand that not all stories are the same and it is an asset to feel ok with having a story that is different from peers. Further, they wrote about the ways that they as new teachers need and want to build authentic relationships with youth. Brian wrote:

If we are to avoid the allure of authority that tempts teachers and instead strive to be servants of our students, we must engage actively in understanding our students' lives. We must move beyond the superficial biographical details of our students and instead view each one of them as the narrator of his or her own life story-or, indeed, as the cartographer of his or her own map of the world.

This sense of building on cultural assets alongside youth was a central theme in students' reflections about this activity as an assignment they would adapt and use in their own $\mathrm{K}-12$ classrooms.

Some pre-service teachers reflected on the need to move beyond a focus on cultural assets for the sake of building community. They wrote about the importance of culturally relevant pedagogy and how they wanted to be continual learners of their students' experiences inside and outside of school. Alex reflected on his need to resist the labels that he knows follow students around school buildings and instead, "encourage students to be able to express themselves meaningfully" in his classroom. Others reflected on this idea by connecting the asset map assignment to the literacies of students and the ways that they hoped for youth in their classrooms to be critical thinkers and active citizens. This came back to the idea of telling stories through the asset maps, seeing the stories of others, and valuing lived experiences as central to effective learning and teaching. Cara connected this to the way she thinks of her future students and how some have already been deemed "behind" or "at risk" by the system: "To be able to name themselves, to know what that name means in society, and how to not let that define them in any way outside of how they define themselves. The ability to do that should not be a right limited to those who have had the privilege to learn."

\section{Consciousness-Raising}

As a part of students' reflections on the asset mapping project as a pedagogical tool, they also wrote about its potential to build collective critical thinking for youth and fellow pre-service teachers. As a part of this theme, students reflected on the importance of naming privilege and ways in which they sought to change the system of schooling.

There was a distinct desire among some students to name the privileges portrayed in the asset maps. This was not only a part of students' own reflections about the personal journey of making and viewing the maps, but also about their thinking as pre-service teachers. In writing about her own participation and desire 
to dig more deeply into issues of race and class, Nicole wrote about the focus on "individual versus systemic assets. Privilege was not a strong aspect in the maps presented." Jasmine connected her own "embarrassment" with not expressing some of the structural assets she had on her map with systemic privileges that valued her whiteness over other races. She wrote about ways to address this with her future students by modeling the acknowledgement of such privileges. She wrote, "This stream of thought has enhanced my critical consciousness. I may not have experienced oppression, but that doesn't mean I cannot participate in the fight against it." Others reflected on the assignment possessing the potential to make students aware of a "deeper level of self-reflection." It was this desire to explore more deeply issues of access and equity in their own experiences that led them to reflect on ways to make such foci a part of their teaching.

To build on the reflections above, students wrote about their work as teachers relating to the enhanced critical thinking of their K-12 students. They expressed the sentiment that their work with youth cannot stop with selfreflection. It has to be connected to larger systemic issues and our collective role in bringing about change. Cara talked about her desires for youth to be able to acknowledge assets as a part of seeing the systemic inequities around them:

I thought about myself, and immediately, I could rattle off my statistics: White, privileged, college graduate, Jewish, LGBTQ, woman, Americanborn, Irish-descent, Liberal, world-traveler, writer, student, educator. I've learned what tables I sit at, and what sitting at those tables means for my status in this society. Some, offer me a normative, dominant and advantaged positionality in our society. Others, offer me a marginalized, stigmatized, and oppressed positionality. And others, depending on the community I'm in, can be either.

She then went on to write about sharing this with youth and working with her K12 students to name the barriers and opportunities they see around them as a part of the asset mapping assignment. It is in the connection of these different layers of cultural assets, that students expressed a desire to bring about systemic change through their pedagogy.

\section{Discussion and Implications}

The themes presented above speak to this group of pre-service teachers' experiences with EAM as an assignment, project, and pedagogical strategy. The themes of Transitions and Multiple Identities for the maps and Navigating Support Systems, Self Consciousness, Process as Pedagogy, and Consciousness Raising for the reflections show the relational, fluid, and collective possibilities of EAM. The maps showcase the connections between students' portrayal of their own identities and the transitions they experience across relationships and contexts. The reflection papers highlight connections between 
students' own processes for creating their maps, and how they wanted to present themselves through their map to classmates. These connections revealed feelings of insecurity and vulnerability while also creating possibilities for risk taking and building community. Students expressed that the entire process (making maps, participating in the gallery walk, and writing the reflection) was a challenging undertaking and that the map and paper required them to reflect in different ways. As such, these different modes of self expression and reflection (visual portrayal and written word) provided multiple layers for students to explore how their own experiences varied from their classmates and how their assets emerged as relational and dynamic (e.g., seeing others' maps enabled students to reflect on their own assets in ways not previously envisioned).

Self-reflection was an overarching theme of both the maps and the papers. Certainly the assignment itself required self-reflection, but the analyses above show that there was strong overlap in how students portrayed and thought about their assets. For example, the power of relationships to support students on their personal journeys and the navigation of different contexts as assets were prominent aspects of both the maps and the reflection papers. These areas of overlap were not monolithic, however, as students described key milestones and accomplishments while also discussing their failures and difficulties in getting there. Further, students named supportive family and peer networks as part of their successes, yet also pointed out that some of these very same networks blinded them to the inequities existing around them. These intricacies show the value of the process of EAM, as different parts of the project created different modes of inquiry for students to engage in meaningful reflection.

There were also important differences in the findings presented above. Namely, the themes of Self-Consciousness, Process as Pedagogy, and Consciousness Raising emerged mainly via students writing about their feelings associated with the maps and the gallery walk. Thus, the papers added a layer of insight into the reflection students were engaged in and how they were beginning to think of EAM as a collective, rather than individual, pursuit. For example, the importance of community - family, friends, teammates, etc.-was portrayed in the maps, and the reflection papers revealed the sensitivities towards, inspiration gained from, and hopes for building community that students' experienced in and through these relationships-even with classmates whom they had only known for a few weeks. In these ways, the themes from the maps and the papers work together to show that EAM had an impact on this groups of students' self reflection and desires to build community (as classmates and as future teachers) through a focus on collective assets.

Ecological asset mapping also emerged as a pedagogical strategy and research method that can be utilized to uncover aspects of self and the individual and has the potential to build upon existing approaches to exploring cultural assets. Futch and Fine (2014) discuss using maps to understand and witness changes and shifts in self over time and space and how the self is situated and made meaningful within and across geographical, social, and cultural spaces. In addition, Futch and Fine elaborate upon how maps also demonstrate how selves 
navigate and negotiate these different spaces, which was an important finding in our ecological asset maps. This notion of navigating and shifting identities over changing contexts also connected to the idea of multiple identities, which resonated with participants in our project. Sirin and Fine (2007) discuss this idea in terms of hyphenated identities and the importance of using maps to "normalize fluidity contradiction, struggle, resilience, and diversity" (as cited in Futch \& Fine, 2014 , p. 49). These complex and multidimensional representations of assets allowed our participants to feel validated, vulnerable, and to build community and solidarity with fellow pre-service teachers in the class.

\section{Limitations}

There are numerous limitations to this study. First, findings are reported for one group of 19 pre-service teacher education students in a specific class in a specific geographic location. Moreover, 11 of the 19 participants were identified racially as White, which limits our exploration of ecological asset mapping in a culturally and racially diverse group. Our findings are not generalizable, and are not intended to be, and reflect the perceptions and experiences of this group only. Given the contextual foundations of EAM, the fact that it was a graded assignment within a given course as part of these students' teacher education program is a further limitation of this study since students may have been motivated to create a map and write a reflection that would be socially desirable in this setting. Certainly, these students might portray and reflect on their cultural assets differently in a different context. Relatedly, this study faced a big challenge that hinders of much of the existing research on assets (e.g., Benson et al., 1998; Martinez, 2010; Moll et al., 1992) —it attempts to explore a fluid, dynamic phenomenon at a static point(s) in time. Our attempt to analyze students' maps and written reflections separately was a way to think about multiple representations of self and cultural assets, but this too limited our ability to draw direct connections between students' visual portrayals and written words. Given these points, it is important to note that EAM is a project in its infancy and the ways in which it affected these students' teaching is beyond the scope of this study. Future studies need to incorporate a longitudinal design and/or follow up with this group of students (and others who participate in EAM) to explore the ways in which such experiences influence pedagogical approaches attempting to focus on K-12 students' assets and issues of equity and access in schools.

\section{Implications}

Despite these limitations, we feel that our approach to EAM, its implementation with pre-service teachers, and the themes we present are important steps forward in the study of cultural assets. Namely, we were attempting to explore the potential impact of a pedagogical strategy focused on 
assets, and our findings suggest opportunities and possibilities for enacting EAM with teacher education and K-12 students. The importance of self-reflection is central to EAM, and we feel that it builds upon Picower's (2012) attention to selflove and knowledge of self in the first element of her framework for social justice teaching. It does so through engaging students in a process where they not only think about their own cultural assets across ecological spaces, but they do so alongside their classmates. The fact that students so clearly named community building as a product of the process of EAM shows that individual assets were named and connected to larger community contexts (e.g., Salazar, Martinez, \& Ortega, 2016). This sense of respect for others towards solidarity further builds upon the second element of Picower's (2012) framework.

Consciousness-raising was a theme that emerged from students' written reflections, and it certainly speaks to Picower's (2012) focus on recognizing social injustices. As the findings show, this was not something that all students expressed, nor was it something that students directly connected to EAM as a pedagogical process. We acknowledge that further research is needed in this area, and we also feel that EAM holds potential to address issues of social injustice in K-12 and teacher education classroom by problematizing the deficit mindset that many teachers hold for communities of Color (Duncan-Andrade, 2007; Yosso, 2005). In this way, we feel that EAM is a possible tool for teachers to build a counternarrative through authentically centering students' lived experiences as a part of curriculum (Camangian, 2010; Vickery, 2016; Villegas et al., 2012).

Our ecological focus (Bronfenbrenner, 1994; Lee, 2008) is a facet of this project that we feel contributes to the study of cultural assets. Our findings show that students' navigation across and in-between cultural contexts was central to their perceptions of their own and others' identities and assets. This is important because we feel that it begins to show the recognition of assets as fluid, shared, and process-oriented. For pre-service teachers to frame assets in such a way is the start of the move away from a solitary focus on pre-determined, static assessments of K-12 students' academic achievement and possibilities for success (Lee et al., 2004). It is a start towards teaching for social justice through directly addressing access and equity as pillars of multicultural education (Convertino, 2016; Picower, 2012). And, it is a way for teachers to break free from some of the oppressive forces of testing and "target students." If teachers can begin this work as a part of their self-reflection, we feel it can transfer to their classrooms and their work with youth. In this way, we think EAM holds the potential to harness the assets of teachers and students in a quest towards critical, self-reflective, asset-based learning that changes lives.

\section{References}


Akom, A. A. (2003). Reexamining resistance as oppositional behavior: The Nation of Islam and the creation of a Black achievement ideology. Sociology of Education, 76(4), 305-325.

Benson, P., Leffert, N., Scales, P., \& Blyth, D. (1998). Beyond the "village" rhetoric: Creating healthy communities for children and adolescents. Applied Developmental Science, 2(3), 138-159.

Borrero, N. E. (2011). Nurturing students' strengths: The impact of a schoolbased student interpreter program on Latino/a students' reading comprehension and English language development. Urban Education, 46(4), 663-688.

Borrero, N. E., Flores, E., \& de la Cruz, G. (2016). Developing and enacting culturally relevant pedagogy: Voices of new teachers of color. Equity and Excellence in Education, 49(1), 27-40.

Borrero, N. E., \& Yeh, C. J. (2010). Ecological language learning among ethnic minority youth. Educational Researcher, 39(8), 571-581.

Borrero, N. E., Yeh, C. J., Cruz, I., \& Suda, J. (2012). School as a context for "othering" youth and promoting cultural assets. Teachers College Record, 114(2), 1-37.

Borrero, N. E., \& Yeh, C. J. (2013). Social class and school counseling: A collaborative, asset-based approach. In W. M. Liu (Ed.), The Oxford handbook of social class in counseling psychology (pp. 303-316). Oxford, UK: Oxford University Press.

Bronfenbrenner, U. (1989). Ecological systems theory. In R. Vasta (Ed.), Six theories of child development: Revised formulations and current issues (Vol. 6). Greenwich, CT: JAI Press.

Bronfenbrenner, U. (1994). Ecological models of human development. In T. Husen \& T. N. Postlethwaite (Eds.), International Encyclopedia of Education (2nd Ed., Vol. 3, pp. 1643-1647). Oxford, UK: Pergamon Press.

Camangian, P. (2010). Starting with self: Teaching autoethnography to foster critically caring literacies. Research in the Teaching of English, 45(2), 179204.

Camangian, P. (2013). Seeing through lies: Teaching ideological literacy as a corrective lens. Equity and Excellence in Education, 46(1), 119-134.

Convertino, C. (2016). Beyond ethnic tidbits: Toward a critical and dialogical model in multicultural social justice teacher preparation. International Journal of Multicultural Education, 18(2), 125-142.

Duncan-Andrade, J. (2007). Gangtas, wankstas, and ridas: Defining, developing, and supporting effective teachers in urban schools. International Journal of Qualitative Studies in Education, 20(6), 617-638.

Freire, P. (1970). Pedagogy of the oppressed. New York, NY: Continuum. 
Futch, V. A., \& Fine, M. (2014). Mapping as a method: History and theoretical commitments. Qualitative Research in Psychology, 11(1), 42-59.

Glaser, B.G., \& Strauss, A.L. (1967). The discovery of grounded theory. Chicago, IL: Aldine.

Gunn, A., Bennett, S., Evans, L. S., Peterson, B. J., \& Welsh, J. L. (2013). Autobiographies in preservice teacher education: A snapshot tool for building a culturally responsive pedagogy. International Journal of Multicultural Education, 15(1), 1-20.

Gutierrez, K., \& Rogoff, B. (2003). Cultural ways of learning: Individual traits or repertoires of practice. Educational Researcher, 32(1), 19-25.

Hawkins, M. R. (2004). Researching English language and literacy development in schools. Educational Researcher, 33(3), 14-25.

Kohli, R. (2009). Critical race reflections: Valuing the experiences of teachers of color in teacher education. Race, Ethnicity and Education, 12(2), 235-251.

Ladson-Billings, G. (2016). "\#Literate lives matter": Black reading, writing, speaking, and listening in the $21^{\text {st }}$ Century. Literacy Research: Theory, Method, and Practice. Advance online publication. doi: $10.1177 / 2381336916661526$

Ladson-Billings, G. (1994). The dreamkeepers: Successful teachers of African American children. San Francisco, CA: Jossey-Bass.

Lee, C. D. (2008). The centrality of culture to the scientific study of learning and development: How an ecological framework in educational research facilitates civic responsibility. Educational Researcher, 37(3), 267-279.

Lee, C. D., Spencer, M., \& Harpalani, V. (2003). "Every eye shut ain't sleep": Studying how people live culturally. Educational Researcher, 32(5), 6-13.

Marshall, E., \& Toohey, K. (2010). Representing family: Community funds of knowledge, bilingualism, and multimodality. Harvard Educational Review, 80(2), 221-242.

Martínez, R. A. (2010). Spanglish as literacy tool: Toward an understanding of the potential role of Spanish-English code-switching in the development of academic literacy. Research in the Teaching of English, 45(2), 124-148.

Moll, L. C., Amanti, C., Neff, D., \& González, N. (1992). Funds of knowledge for teaching: Using a qualitative approach to connect homes and classrooms. Theory into Practice, 31(2), 132-141.

Nieto, S. (2002). Language, culture, and teaching: Critical perspectives for a new century. Mahwah, NJ: Lawrence Erlbaum Associates.

Olsen, L. (1997). Made in America: Immigrant students in our public schools. New York, NY: New Press. 
Orellana, M. F., \& Bowman, P. (2003). Cultural diversity research on learning and development: Conceptual, methodological, and strategic considerations. Educational Researcher, 32(5), 26-32.

Paris, D. (2010). The second language of the United States: Youth perspectives on Spanish in a changing multiethnic community. Journal of Language, Identity \& Education, 9(2), 139-155.

Picower, B. (2012). Using their words: Six elements of social justice curriculum design for the elementary classroom. International Journal of Multicultural Education, 14(1), 1-17.

Salazar, M. C., Martinez, L. M., \& Ortega, D. (2016). Sowing the semillas of critical multicultural citizenship for Latina/o undocumented youth: Spaces in school and out of school. International Journal of Multicultural Education, 18(1), 88-106.

Sirin, S. R., \& Fine, M. (2008). Muslim American youth: Understanding hyphenated identities through multiple methods. New York, NY: New York University Press.

Strauss, A., \& Corbin, J. M. (1998). Basics of qualitative research: Techniques and procedures for developing grounded theory. Newbury Park, CA: Sage.

Taylor, S. J., \& Bogdan, R. (1998). Introduction to qualitative research methods $\left(3^{\text {rd }}\right.$ ed.). Hoboken, $\mathrm{NJ}$ : Wiley.

Valenzuela, A. (1999). Subtractive Schooling. Albany, NY: SUNY Press.

Vickery, A. E. (2016). "I worry about my community": African American women utilizing communal notions of citizenship in the social studies classroom. International Journal of Multicultural Education, 18(1), 28-44.

Villegas, A. M., \& Lucas, T. (2002). Preparing culturally responsive teachers: Rethinking the curriculum. Journal of Teacher Education, 53(1), 21-26.

Villegas, A., Strom, C., \& Lucas, T. (2012) Closing the racial/ ethnic gap between students of color and their teachers: An elusive goal. Equity \& Excellence in Education, 45(2), 285-288.

Vygotsky, L. (1978). Mind and society. Cambridge, MA: Harvard University Press.

Yeh, C. J., Borrero, N. E., Tito, P., \& Petaia, L. S. (2014). Intergenerational stories of "othered" youth through insider cultural knowledge and community assets. The Urban Review, 46(2), 225-243.

Yosso, T. J. (2005). Whose culture has capital? A critical race theory discussion of community cultural wealth. Race Ethnicity and Education, 8(1), 69-91. 


\section{Author Contact}

Noah Borrero: neborrero@usfca.edu

University of San Francisco, 2130 Fulton St, San Francisco, California, 94117

Christine Yeh: cjyeh@usfca.edu

University of San Francisco, 2130 Fulton St, San Francisco, California, 94117 